\title{
Effects of CpG-B ODN on the protein expression profile of swine PBMC
}

\author{
Govindarajulu NAGARAJAN ${ }^{\mathrm{a} *}$, Cheng-Chin KUO ${ }^{\mathrm{a} *}$, Chi-Ming LIANG ${ }^{\mathrm{b}, \mathrm{c}, \mathrm{d}}$, \\ Chi-Min CHEN $^{\mathrm{e}}$, Shu-Mei LIANG ${ }^{\mathrm{a}, \mathrm{b} * *}$ \\ ${ }^{a}$ Agricultural Biotechnology Research Center, Academia Sinica, No. 128, Academia Road, Sec. 2, \\ 11529 Taipei, Taiwan \\ ${ }^{\mathrm{b}}$ Genomics Research Center, Academia Sinica, No. 128, Academia Road, Sec. 2, 11529 Taipei, Taiwan \\ ${ }^{\mathrm{c}}$ Institute of Biological Chemistry, Academia Sinica, No. 128, Academia Road, Sec. 2, \\ 11529 Taipei, Taiwan \\ ${ }^{\mathrm{d}}$ Division of Molecular and Genomic Medicine, National Health Research Institutes, Miaoli, Taiwan \\ ${ }^{\mathrm{e}}$ Division of Animal Medicine, Animal Technology Institute Taiwan, Miaoli, Taiwan
}

(Received 15 September 2006; accepted 26 April 2007)

\begin{abstract}
The CpG motif within bacterial DNA is a potent immuno-stimulatory moiety. Here, using a 2-D electrophoretic approach, we investigated the effect of synthetic oligodeoxynucleotide containing a $\mathrm{B}$ type $\mathrm{CpG}$ motif (CpG-B ODN) on the protein expression profile of swine peripheral blood mononuclear cells (PBMC). We found that several proteins including spondin 1, $\mathrm{N}$-acetolactate alpha linked acidic dipeptidase; V kappa light chain, T cell receptor variable alpha chain, heat shock protein (Hsp) 60, Hsp70, KIAA0857 protein, and PNAS-146 were up-regulated in PBMC by CpG-B ODN stimulation. Further studies showed that CpG-B ODN-mediated Hsp60, Hsp70 and Hsp90 expressions were closely associated with the TLR9 signalling pathway. Pretreatment with inhibitors of Hsp70, Hsp90 and TLR9 all blocked the CpG-B ODN-mediated anti-apoptotic effect in swine PBMC. These results suggest that $\mathrm{CpG}-\mathrm{B}$ ODN treatment of swine PBMC may enhance the expression of biologically active proteins, notably spondin 1, V kappa light chain, T cell receptor variable alpha chain and Hsps, which may play an important role in CpG-B ODN-mediated activation of immune responses and enhancement of swine PBMC survival.
\end{abstract}

heat shock proteins / CpG ODN / TLR9 / proteomics / apoptosis

\section{INTRODUCTION}

The mammals utilise innate and adaptive immunity to protect themselves against microbial infections. The microbial DNA that contains the unmethylated CpG motif (CpG DNA) stimulates not

\footnotetext{
* These two authors contributed equally to this work.

** Corresponding author:

smyang@gate.sinica.edu.tw
}

only a rapid innate response but also the development of pathogen-specific adaptive immunity $[13,16]$. In comparison, vertebrate DNA is not immunostimulatory due to the methylation of its $\mathrm{CpG}$ dinucleotides $[7,18]$. The immunostimulatory effects of microbial $\mathrm{CpG}$ DNA can be mimicked by synthetic oligodeoxynucleotides containing a $\mathrm{CpG}$ motif $(\mathrm{CpG}$ ODN) [19]. CpG ODN can be classified into two major classes: type A (CpG-A 
ODN) and type B (CpG-B ODN) [19]. CpG-A ODN are effective in activating NK cells and stimulating plasmacytoid dendritic cells (pDC) and macrophages to produce high levels of interferon $\alpha$ (IFN- $\alpha)$ [24, 38]. In contrast, CpG-B ODN primarily stimulate proliferation of B cells as well as secretion of immunoglobulins, IL-6 and IL-10. CpG-B ODN also induce maturation and activation of pDC and macrophages [14, 38]. CpG-B ODN protect $\mathrm{B}$ cells and pDC against spontaneous apoptosis and rescue WHEI-231 B cells from apoptosis induced by $\operatorname{IgM}[31,39,40]$. They also protect mouse spleen cells as well as RAW264.7 macrophages and human RPMI 8226 $B$ cells against $\gamma$-irradiation-induced apoptosis [35].

Toll-like receptors (TLR) play crucial roles in early host defense against invading pathogens [5]. So far, 13 mammalian TLR paralogues have been identified $[6,36]$. Among these TLR, TLR9 recognises bacterial and viral DNA containing a $\mathrm{CpG}$ motif $[3,25]$. After binding of ligands such as CpG DNA, TLR9 signalling is initiated by the recruitment of the adaptor molecule myeloid differentiation marker 88 (MyD88) via the cytoplasmic Toll/IL-1R (TIR) domain of TLR9 [12]. Recruitment of MyD88 is followed by the engagement of IL-1 receptor-associated kinase (IRAK) and the adaptor protein tumour necrosis receptor associated factor 6 (TRAF6). Oligomerisation of TRAF6 can activate the inhibitor of kappa B (IкB) kinase complex $[1,12,17]$, which comprises two catalytic subunits, the I $\mathrm{B}$ kinase (IKK) $\alpha$ and IKK $\beta$, and a regulatory subunit, IKK $\gamma$. The activation of the IKK complex causes the phosphorylation, ubiquitination and degradation of $\mathrm{I} \kappa \mathrm{B}$, resulting in the phosphorylation of $\mathrm{p} 65 \mathrm{NF}-\mathrm{\kappa B}$ subunit [26] and/or translocation of $N F-\kappa B$ to the nucleus, and subsequently activating the NF- $\mathrm{KB}$-dependent genes, such as TNF- $\alpha$, IL-1 and IL-6 [19]. In addition to $\mathrm{NF}-\kappa \mathrm{B}$, several protein kinases such as p38 mitogen-activated protein kinase (MAPK), extracellular signal-regulated kinase (ERK), c-Jun NH2-terminal kinase (JNK) and phosphatidylinositol-3-kinase (PI3K) $[2,23,37]$ are associated with the TLR9 signalling pathway.

Livestock are considered to be useful surrogates for human models in both basic and applied studies [29]. However, only little information has been documented concerning the mechanism of CpG ODN action on swine immune cells [10, 15,34]. Therefore, we studied the effect of $\mathrm{CpG}$ $\mathrm{B}$ ODN on protein expression profiles and biological functions in swine peripheral blood mononuclear cells (PBMC).

\section{MATERIALS AND METHODS}

\subsection{Reagents}

CpG-B ODN which is a stimulator for the TLR9 signalling pathway in a variety of cells [27] (ODN2006; tcg tcg ttt tgt cgt ttt gtc gtt) and control GpC ODN (ODN2137; tgc tgc ttt tgt gct ttt gtg ctt) were purchased from MDBio Inc. (Taipei, Taiwan). Mouse monoclonal antibodies against human-Hsp60, humanHsp70 and water mold-Hsp90 that crossreacted respectively with swine Hsp60, Hsp70 and Hsp90 were obtained from StressGen Biotechnologies (Victoria, BC, Canada). Chicken anti-spondin 1 polyclonal antibodies were purchased from $\mathrm{Ab}$ cam (Cambridge, UK). Secondary goat antibodies against mouse $\operatorname{IgG}$ and chicken IgG were purchased from Pierce (Rockford, USA) and Abcam, respectively. Radicicol, an Hsp90 inhibitor that binds to the ATP binding pocket of Hsp90 to disrupt its function by preventing ATP hydrolysis [28], Hsp70 synthesis inhibitor quercetin [22] and TLR9 signalling inhibitor chloroquine [11] as well as all media and medium additives were purchased from Sigma (St. Louis, MO, USA). 


\subsection{Isolation of swine PBMC}

The blood from a specific pathogen-free pig was collected via venipuncture directly into cell preparation tubes with sodium citrate (CPT tube; BD Biosciences). PBMC were isolated using Ficoll-Paque (Amersham Pharmacia Biotech) density gradient centrifugation [10].

\subsection{Preparation of protein samples from PBMC}

About $5 \times 10^{7}$ swine PBMC were seeded in RPMI 1640 medium supplemented with $10 \%$ FBS and $1 \%$ penicillinstreptomycin followed by $1 \mu \mathrm{M}$ of $\mathrm{GpC}$ ODN or CpG-B ODN stimulation for $24 \mathrm{~h}$ at $37{ }^{\circ} \mathrm{C}$. The treated cells were sonicated at $4{ }^{\circ} \mathrm{C}$ in $25 \mathrm{mM}$ of Tris ( $\left.\mathrm{pH} 7.4\right)$. The homogenate was then centrifuged at $10000 \times g$ for $10 \mathrm{~min}$ using a Beckman Avanti J-25 centrifuge. The protein concentration of the supernatant was determined using the Bio-Rad Protein Assay (Bio-Rad Laboratories, Hercules, CA, USA) with BSA as a standard.

\subsection{Two-dimensional gel electrophoresis}

Two-dimensional gel electrophoresis was performed using an IEF and a Hofer DALT vertical unit (Amersham Biosciences, Piscataway, NJ, USA). One milligram of dried protein sample was dissolved in $350 \mu \mathrm{L}$ of rehydration buffer solution, containing $7 \mathrm{M}$ urea, $2 \mathrm{M}$ thiourea, $4 \% \mathrm{w} / \mathrm{v}$ CHAPS, $5 \mathrm{mM}$ tributyl phosphine, and 2\% IPG and loaded onto an immobilised $\mathrm{pH}$ 3-10 non-linear gradient strip $(18 \mathrm{~cm})$, followed by rehydration for $16 \mathrm{~h}$. IEF was performed in the following manner: $500 \mathrm{~V}$ for $1 \mathrm{~h}, 1000 \mathrm{~V}$ for $1 \mathrm{~h}$ and $8000 \mathrm{~V}$ for $6 \mathrm{~h}$. At the end of IEF, the IPG strips were equilibrated for $10 \mathrm{~min}$ in buffer containing $6 \mathrm{M}$ urea, $2 \% \mathrm{w} / \mathrm{v}$
SDS, $30 \% \mathrm{v} / \mathrm{v}$ glycerol, and $50 \mathrm{mM}$ Tris, $\mathrm{pH} 6.8$, then reduced with $65 \mathrm{mM}$ dithiorerythritol (DTE) followed by alkylation with $135 \mathrm{mM}$ iodoacetamide for another 15 min. After equilibration, the IPG strips were immediately placed on top of a $12 \%$ SDS-PAGE $(1.5 \mathrm{~mm}, 20 \mathrm{~cm} \times 24 \mathrm{~cm})$. The second dimension gels were then overlaid with melt $0.8 \%$ agarose solution in SDS electrophoresis buffer. Electrophoresis was performed at $16{ }^{\circ} \mathrm{C}$, starting at $10 \mathrm{~m} \AA$ per gel for $1 \mathrm{~h}$, followed by $45 \mathrm{~m} \AA$ per gel until the dye front reached the bottom of the gels.

\subsection{SYPRO-Ruby staining and image acquisition}

Immediately after electrophoresis, the gels were stained with SYPRO Ruby (Molecular Probes, Eugene, OR, USA). In brief, the gels were fixed for $30 \mathrm{~min}$ in fixative/destain solution containing $10 \%$ methanol and $7 \%$ acetic acid, and then stained overnight in SYPRO Ruby stain. The staining solution was removed and the gels were washed in fixative/destain solution for $3 \mathrm{~h}$. After staining, image acquisition was carried out on a Typhoon 9200 scanner (Amersham Pharmacia Biotech). To identify a protein, spot detection, quantification and matching of 2D results were performed using Image Master ${ }^{\mathrm{TM}}$ software (Amersham Bioscience). The molecular weights of the proteins were calibrated according to the LMW-SDS Marker Kit (Amersham Bioscience), and their pI values were estimated from the position of the protein spots on the $2 \mathrm{D}$ gel and confirmed with the information supplied by the manufacturer. Since most of the pI values for the truncated proteins had not been reported previously, the $\mathrm{pI}$ values of the truncated proteins were estimated from the position of the observed spots. To omit the variation due to the use of separate gels, after background subtraction, the intensity levels of protein spots on each gel 
were normalised as a proportion of one reference spot, and protein quantities were calculated by integrating the density over the spot area. Protein spots that showed reproducible modulation exceeding $\sim 80 \%$ after CpG-B ODN treatment in three separate experiments were further analysed by mass spectrometry.

\subsection{In Gel Trypsin digestion}

Protein spots of interest were excised from the SYPRO Ruby stained gels and digested with sequencing grade modified trypsin (Trypsin In-Gel digest kit, Sigma) according to the manufacturer's protocol with modification [33].

\subsection{MALDI-TOF analysis}

Protein spots were excised from stained gels and digested in gel with trypsin as previously described. Tryptic peptide analyses were performed with the use of a Micromass Q-TOF Ultima ${ }^{\mathrm{TM}}$ MALDI (Micromass, Wythenshawe, UK). Peptide mixtures $(1 \mu \mathrm{L})$ were pre-mixed with $1 \mu \mathrm{L}$ of the matrix (5 mg $\alpha$-cyano-4hydroxycinnamic acid in 50\% acetonitrile with $0.1 \%$ TFA) then spotted onto the MALDI target plate. Mass spectra were acquired for the mass range of 900-3500 Da and the individual spectrum from MALDI MS or MS/MS was processed by use of the Micromass MassLynx ${ }^{\mathrm{TM}}$ 4.0. The generated peak list files were used to query the NCBI database with the MASCOT program $^{1}$ and the following parameters: peptide mass tolerance, $50 \mathrm{ppm}$; MS/MS ion mass tolerance, $0.25 \mathrm{Da}$; allowance of missed cleavage, 1 ; and consideration for variable modifications such as oxidation of methionine and carboxyamidomethylation of cysteines.

\subsection{LC MS/MS analysis}

The peptide samples extracted from the spots were subjected to Micromass Q-

\footnotetext{
${ }^{1}$ http://www.matrixscience.com
}

TOF Ultima API, hybrid quadruple orthogonal acceleration time-of-flight tandem mass spectrometry (Micromass, Ltd, UK). The columns were packed under nitrogen gas pressure using a vessel. Four microliters of each mixture were injected into the column. The samples were analysed with a gradient program consisting of a 5 min initial isocratic elution with $0 \% \mathrm{~B}$, followed by a linear gradient 0 $70 \% \mathrm{~B}$ and a linear gradient $70-0 \% \mathrm{~B}$ for $15 \mathrm{~min}$ (A-water-0.1\% formic acid, B-90\% acetonitrile- $10 \%$ water- 0.1 formic acid). Peptides were eluted at a $400-\mathrm{nL} / \mathrm{min}$ flow rate and introduced online into the mass spectrometer. MS and MS/MS spectra were acquired in the data-dependent mode; the instrument cycled through the acquisitions from the full scan MS spectrum followed by five MS/MS scans of the most abundant ions from the MS scan. The MS/MS data were searched against a subset of mammalian proteins from the NCBI protein sequence database.

\subsection{Western blot analysis}

Fifty micrograms of total protein from each treatment were separated electrophoretically by SDS-PAGE (12.5\%) and used for western blot analysis. Pre-stained protein markers (Invitrogen) were used to identify positions of various proteins on the gel. Proteins were electro-blotted onto a nitrocellulose membrane using the Hoefer Semi Phore (Amersham Biosciences) Trans blot electrophoretic transfer unit set at $125 \mathrm{~m} \AA$ for $1.5 \mathrm{~h}$. The membranes were blocked in PBS-0.1\% Tween 20 (PBST) containing 5\% non-fat skimmed milk at room temperature for $1 \mathrm{~h}$, and then stained with specific primary antibody. The membranes were then incubated with horseradish peroxidase-conjugated secondary antibody (dilution, 1:3 000) for 1 h. After washing with PBST for three times, immuno-reactivity signals were detected on an X-Ray film by using the 
Super Signal West Pico Chemiluminescent substrate kit (Pierce, Rockford, USA), and the bands were quantified using Kodak ID 2.0 Image Analysis software (Kodak Scientific Imaging Systems, New Haven, USA).

\subsection{Cell viability assay}

Experiments on resting murine spleen B cells and dendritic cells have demonstrated that $\mathrm{CpG}$ ODN can protect cells from spontaneous apoptosis $[31,40]$, thus the antiapoptotic effect of $\mathrm{CpG}$ ODN on swine PMBC was investigated. Swine PBMC were cultured for $60 \mathrm{~h}$ in serum containing (10\% FBS) or serum-free medium with or without CpG-B ODN in the presence or absence of inhibitors. After treatment, cell viability was determined by trypan blue exclusion. In brief, $20 \mu \mathrm{L}$ of cell suspension was mixed with $20 \mu \mathrm{L}$ of trypan blue (Sigma), and the cells were then counted using a hemacytometer. The ratio of dead cells (blue) to the total cells in each experiment was determined by counting four different fields.

\subsection{DNA Fragmentation Assay}

Swine immune cells were used to extract the genomic DNA using a genomic DNA extraction kit (Gene-Spin ${ }^{\mathrm{TM}}$, Taiwan) according to the manufacturer's protocol. Electrophoresis of resulting DNA was carried out on $1.5 \%$ horizontal agarose gel and the results were visualised by ethidium bromide staining.

\section{RESULTS}

\subsection{Protein expression profiles of $\mathrm{CpG}$ - B ODN-stimulated swine PBMC}

We previously treated swine PBMC with various synthetic $\mathrm{CpG} O \mathrm{ODN}$ and found that ODN2006, a type B CpG ODN
(CpG-B ODN), had the ability to stimulate the proliferation of swine PBMC. In this study, we further tested if ODN2006 has any effect on swine PBMC cytokines. Both mRNA levels of IL-6 and IL-12 in swine PBMC were increased after 4 h ODN2006 stimulation whereas control GpC ODN2006 (ODN2137) has no enhancement effect (Fig. 1).

We further employed a two-dimensional gel electrophoresis technique to study the effect of CpG-B ODN on protein expression profiles of swine immune cells. After $24 \mathrm{~h}$ CpG-B ODN stimulation, we found that the intensities of eight protein spots were increased by more than $80 \%$ as compared to those of the control (Fig. 2). These protein spots were individually excised from gels for further identification. After trypsin digestion, three protein spots were identified as Hsp60, Hsp70 and T cell receptor variable alpha chain, respectively, by comparing their MALDI-TOF (Tab. I) results with the currently available swine protein database. The identity of Hsp70 was verified by LC/MS/MS analysis (Tab. II). Increased levels of Hsp60 and Hsp70 induced by CpG-B ODN in swine PBMC were further confirmed by western blot analyses (Fig. 3A). In addition, Hsp90, a protein known to be up-regulated by $\mathrm{CpG}$ ODN treatment of THP 1 cells, was also up-regulated in swine PBMC. Amongst the three stress proteins tested, Hsp60 showed the greatest increase in expression (3.4 fold) followed by Hsp70 (2.8 fold) and then Hsp90 (2.3 fold) upon CpG-B ODN treatment. In comparison, none of these three proteins were increased after negative control of GpC ODN treatment (Fig. 3A). As to the identities of the other up-regulated protein spots, we used broader MS database without setting species limitation to search for their identities since not many swine protein sequences had been identified to date. Our results showed that the other five proteins are most likely spondin1 (f-spondin), 


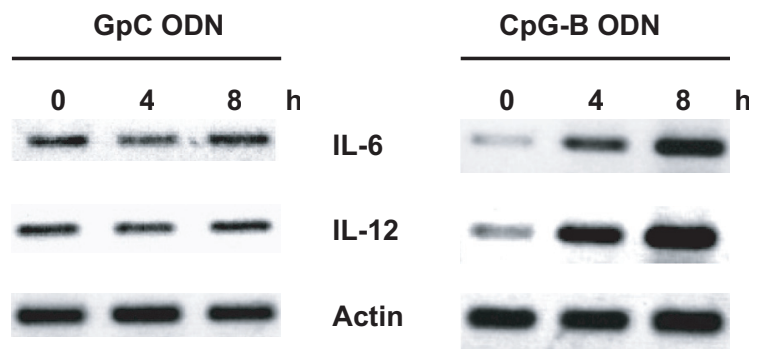

Figure 1. Enhancement of IL-6 and IL-12 mRNA expression by CpG-B ODN. Swine PBMC were stimulated with GpC ODN or CpG-B ODN for the times indicated. RT-PCR was then performed to analyse IL-6 and IL-12 expression. $\beta$-actin was used as an internal control. The experiment was repeated twice with similar results.

Table I. List of cellular proteins up-regulated by CpG-B ODN in swine PBMC.

\begin{tabular}{lcccc}
\hline $\begin{array}{l}\text { Protein } \\
\text { spot No. }\end{array}$ & $\begin{array}{c}\text { Protein } \\
\text { Name }\end{array}$ & $\begin{array}{c}\text { Accession } \\
\text { No. }\end{array}$ & $\begin{array}{c}\text { MW (kDa) } \\
\text { (Gel/theor. })\end{array}$ & $\begin{array}{c}\text { pI } \\
\text { (Gel/theor. })\end{array}$ \\
\hline 1 & Heat shock protein 60 & gi38503406 & $59 / 57.8$ & $6.8 / 5.2$ \\
2 & Heat shock protein 70 & gi1978 & $70 / 70.1$ & $6.2 / 6.0$ \\
3 & PNAS-146 & AAK07555 & $39.8 / 70.7$ & $7.2 / 6.5$ \\
4 & Spondin1 (f-spondin) & gi110347423 & $91.0 / 91.2$ & $6.5 / 3.2$ \\
5 & KIAA0857 & gi4240203 & $78.1 / 78.3$ & $5.1 / 5.8$ \\
6 & V-kappa light chain & gi758154 & $12.8 / 10.9$ & $4.4 / 6.7$ \\
7 & N-Acetolactate alpha linked acidic dipeptidase & gi4885505 & $83.5 / 82.0$ & $4.5 / 4.6$ \\
8 & T cell receptor variable alpha chain & gi245754 & $29.4 / 26.5$ & $7.4 / 6.9$ \\
\hline
\end{tabular}

The identity, NCBI database accession number, theoretical and apparent molecular weight and $\mathrm{pI}$ of the proteins were indicated.

Table II. LC MS/MS analyses of Hsp70 identified in 2D gel.

\begin{tabular}{lccccc}
\hline $\begin{array}{l}\text { Residue } \\
\text { number }\end{array}$ & $\mathrm{M} / \mathrm{Z}$ & Mr. (expt) & Mr. (calc) & Sequence & Ions score \\
\hline $588-597$ & 581.293 & 1160.572 & 1160.586 & MQELAQVSQK & 46 \\
$305-315$ & 643.825 & 1285.636 & 1285.688 & LESLVEDLVNR & 53 \\
$503-514$ & 645.803 & 1289.592 & 1289.610 & ASSGLNEDEIQK & 75 \\
$168-183$ & 830.424 & 1658.834 & 1658.888 & IINEPTAAALAYGLDK & 91 \\
$271-294$ & 1266.616 & 2531.217 & 2531.275 & IELSSAQQTDVNLPYITADATGPK & 92 \\
$422-445$ & 885.085 & 2652.233 & 2652.289 & HSQVFSTAEDNQSAVTIHVLQGER & 97 \\
$322-345$ & 1221.112 & 2440.210 & 2440.281 & VALQDAGLSVSDIDDVILVGGQTR & 117 \\
\hline
\end{tabular}


A

\section{GpC ODN}

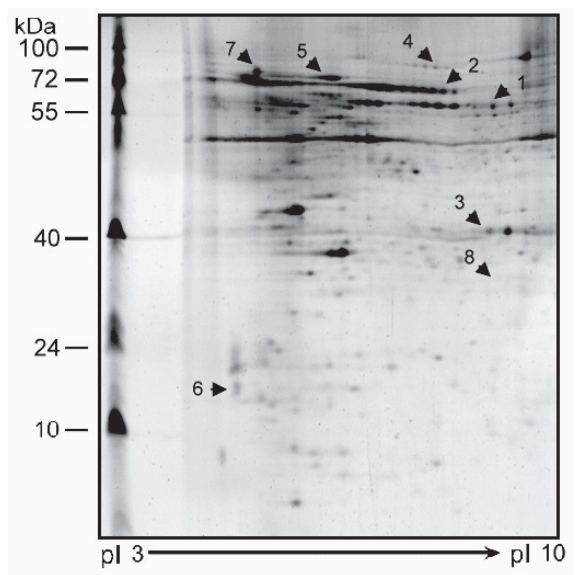

CpG-B ODN

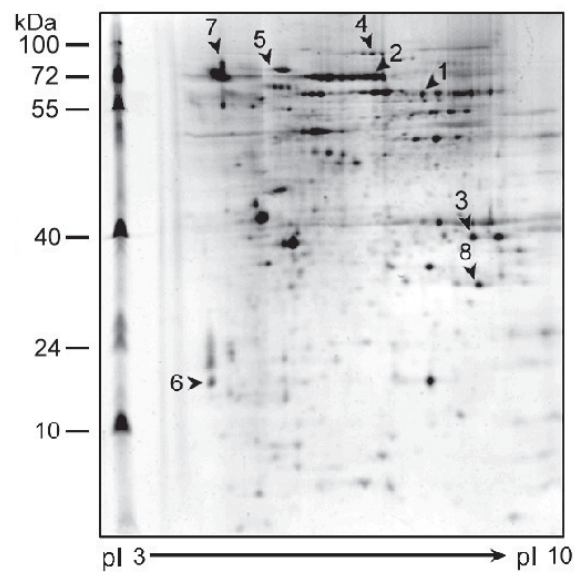

B

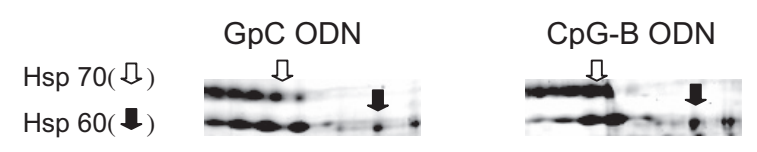

Figure 2. Two dimensional gel electrophoretic (2-DE) analyses of cellular proteins of swine PBMC after CpG-B ODN stimulation. (A) Swine PBMC cells were treated with $1 \mu \mathrm{M}$ GpC ODN or CpGB ODN for $24 \mathrm{~h}$. Cellular proteins were extracted and separated by 2-DE. The arrows indicate protein spots up-regulated by CpG ODN treatment. (B) Enlarged view of Hsp 60 (spot 1) and Hsp70 (spot 2) after CpG-B ODN and GpC ODN treatment. The experiment was repeated 3 times with similar results. 

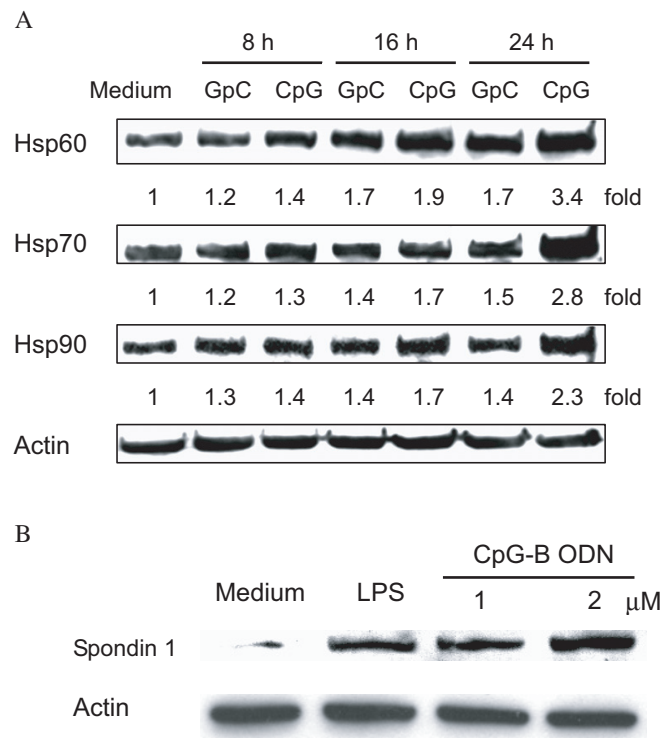

Figure 3. Enhancement of Hsp and spondin 1 expression by $\mathrm{CpG}-\mathrm{B}$ ODN in swine PBMC. (A) Swine PBMC cells were incubated with $1 \mu \mathrm{M}$ CpG-B ODN or GpC ODN for the times indicated. The protein expression levels of Hsp were determined by Western blotting with anti-Hsp60, anti-Hsp70 and anti-Hsp90 antibodies. The bands corresponding to the various proteins were quantified by densitometry and normalised to $\beta$-actin levels within the same sample. Enhancements of Hsp expression are presented as the fold increased compared with the control. (B) Swine PBMC cells were incubated with medium, CpG-B ODN or LPS (100 ng/mL) for $24 \mathrm{~h}$. The protein expression level of spondin 1 was determined by Western blotting with anti-spondin 1 antibodies. One representative experiment out of three is shown.

KIAA0857 protein, V kappa light chain, $\mathrm{N}$-acetolactate alpha linked acidic dipeptidase and PNAS-146 (Tab. I). Western blot analyses also confirmed that CpG-B ODN increased the expression of spondin 1 in a dose-dependent manner as compared to medium (Fig. 3B). LPS, a sensitive stimulator of immune cells, also had an effect on spondin 1 expression of swine PBMC (Fig. 3B).

\subsection{Requirement of TLR9 for CpG-B ODN-induced expression of Hsp in swine PBMC}

It is well known that $\mathrm{CpG}$ ODN is a stimulator for the TLR9 signalling pathway in a variety of cells. Since binding of
CpG ODN to TLR9 requires endosomal maturation, chloroquine, an inhibitor for TLR9 signalling, was used to study the dependency of CpG-B ODN on TLR9 signal pathway of swine PBMC. We found that the expression of Hsp induced by CpG-B ODN treatment decreased in swine PBMC pretreated with chloroquine (both $1 \mu \mathrm{g}$ and $2 \mu \mathrm{g} / \mathrm{mL}$ ) (Fig. 4A). Furthermore, TLR deficient HEK cells stimulated with CpG-B ODN for 8, 16 and $24 \mathrm{~h}$ showed no significant changes in the levels of Hsp expression at different time points, and different ODN tested (data not shown). To rule out the possibility that $\mathrm{CpG}-\mathrm{B}$ ODN may up-regulate Hsp indirectly through other CpG-B ODN-induced soluble factors, we performed a supernatant 


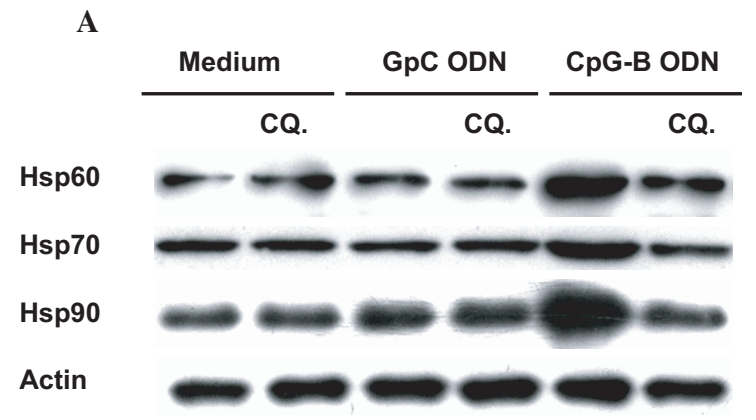

B

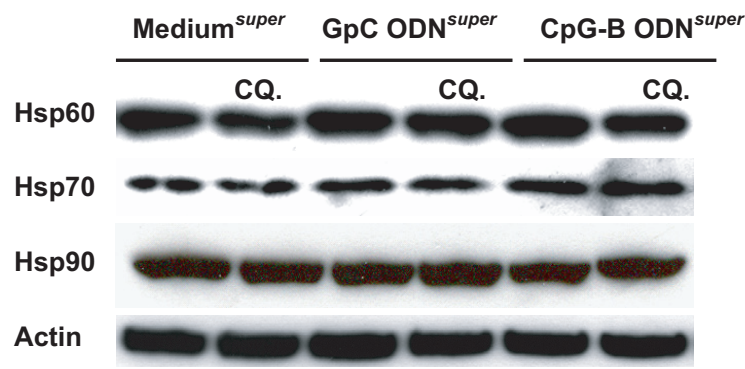

Figure 4. The effect of chloroquine on CpG-B ODN-mediated up-regulation of Hsp. Swine PBMC were stimulated with medium, GpC ODN or CpG-B ODN $(1 \mu \mathrm{M})$ for $24 \mathrm{~h}$ in the presence or absence of chloroquine (CQ., $1 \mu \mathrm{g} / \mathrm{mL}$ ) as indicated. (A) After incubation, the cells were lysed and subjected to Western blotting analysis using anti-Hsp60, anti-Hsp70 and anti-Hsp90 antibodies. (B) PBMC were cultured with growth medium, CpG-B ODN or GpC ODN in the presence or absence of chloroquine for $24 \mathrm{~h}$, the cultured supernatants $(2 \mathrm{~mL})$ were transferred to the fresh culture of PBMC for another $24 \mathrm{~h}$ stimulation. The cells were then lysed and subjected to Western blotting analysis using anti-Hsp60, anti-Hsp70 and anti-Hsp90 antibodies. One representative experiment out of three is shown.

transfer experiment. The culture supernatant of CpG-B ODN stimulated PBMC was transferred to the fresh culture of PBMC and the expression level of Hsp was analysed after $24 \mathrm{~h}$ incubation. We found that the culture supernatant of $\mathrm{CpG}$ B ODN stimulated PBMC did not enhance the expression level of Hsp (Fig. 4B), indicating that the supernatant contains neither sufficient amounts of residual CpG-B ODN nor soluble factors that can increase the Hsp expression. Taken together, these results suggest that $\mathrm{CpG}-\mathrm{B}$ ODN increases expression of Hsp in swine immune cells directly via the TLR9 signalling pathway.

\subsection{Effect of CpG-B ODN-induced Hsp70 and/or Hsp90 on the cell apoptosis of swine PBMC}

Experiments on resting murine spleen B cells and dendritic cells have demonstrated that CpG ODN can protect cells from spontaneous apoptosis. Here, we found that culture of swine PBMC in serum free medium for $48 \mathrm{~h}$ resulted in apoptosis as indicated by the enhancement of DNA fragmentation and about a $30 \%$ decrease in cell viability (Fig. 5). The addition of CpG-B ODN to cells cultured in serum-starved media improved the cellular viability, whereas $\mathrm{GpC}$ 
ODN (negative control) had no effect on viability (Fig. 5A). This effect of CpGB ODN was accompanied by a decrease in cellular DNA fragmentation (Fig. 5B), suggesting that $\mathrm{CpG}-\mathrm{B}$ ODN elicits antiapoptotic signals to swine immune cells.

Since Hsp are known to regulate apoptosis, we then examined whether Hsp70 and Hsp90 play a critical role in CpG-B ODNmediated anti-apoptosis. Although neither radicicol $(0.15 \mu \mathrm{M})$, an Hsp90 inhibitor that binds to the ATP binding pocket of Hsp90 to disrupt its function by preventing ATP hydrolysis, nor quercetin $(5 \mu \mathrm{M})$, an Hsp70 synthesis inhibitor, caused any significant effect on cell viability and DNA fragmentation of PBMC (Tab. III and Fig. 5), they modulated the anti-apoptotic effect of CpG-B ODN in swine immune cells in a dose-dependent manner (Fig. 5). These results suggest that induction of Hsp70 and Hsp90 by CpG-B ODN may play a functional role in CpG-B ODNinduced anti-apoptosis of swine immune cells.

\section{DISCUSSION}

In the present study, we used a 2D gel electrophoresis approach to examine the protein profiles in $\mathrm{CpG}-\mathrm{B}$ ODN treated swine PBMC. Since only few swine protein sequences had been identified and published in databases, the MS results that we used to query the database were set without species limitation. In this way, we identified several CpG-B ODN up-regulated protein spots from 2D gels. Among these proteins, enhancement of spondin 1 expression was identified and confirmed by western blot analysis (Fig. 3B). Spondin 1 is an extracellular matrix attached molecule that promotes neurite outgrowth [8]. It has been associated with inflammatory processes in the nervous system [32]. To our knowledge, our finding is the first to show that CpGB ODN up-regulates spondin 1 in either swine PBMC or any kind of cells. It will be interesting to examine whether $\mathrm{CpG}-\mathrm{B}$ ODN may affect the development of neurite outgrowth, development or differentiation through its up-regulation of spondin1. Among the proteins up-regulated by CpG-B ODN, N-acetolactate alpha linked acidic dipeptidase has been implied to be involved in neurodegenerative disorders [30]. The correlation between Nacetolactate alpha linked acidic dipeptidase and the cellular effect of CpG-B ODN on PBMC and neurodegenerative diseases, nonetheless, remains to be evaluated.

Although CpG ODN has been shown to increase the immunoglobulin secretion in the murine model [19], whether the same effect can be found for swine has not been shown. In this study, we found that CpG-B ODN increased the level of the V kappa light chain (Tab. I), suggesting that $\mathrm{CpG}-\mathrm{B}$ ODN treatment may increase immunoglobulin secretion in swine PBMC. The enhancement in T cell receptor variable alpha chain (Tab. I) of swine PBMC by CpG-B ODN was consistent with the finding that $\mathrm{CpG}$ ODN increases the $\mathrm{T}$ cell receptor $\mathrm{V}$ beta gene of human THP-1 cells [21]. Taken together, these results suggest that like those of humans and mice [19], the swine immune cells may also be affected by CpG-B ODN.

Previously, we have reported upregulation of $\mathrm{Hsp} 60$ and $\mathrm{Hsp} 90$ in $\mathrm{CpG}$ ODN treated THP1 cells [21]. Kumaraguru et al. [20] also found that murine macrophages stimulated with OVA and unmethylated $\mathrm{CpG}$ ODN induced Hsp70 and Hsp90. Here, we showed that the expression levels of Hsp60, Hsp70 and Hsp90 were increased by CpG-B ODN stimulation in swine PBMC (Figs. 2 and $3 \mathrm{~A}$ ). Although there are differences in terms of the structures of the $\mathrm{CpG}$ ODN and the species of the cells used in these studies, it is fair to conclude that CpG ODN may up-regulate Hsp in the mammalian immune cells. 
A

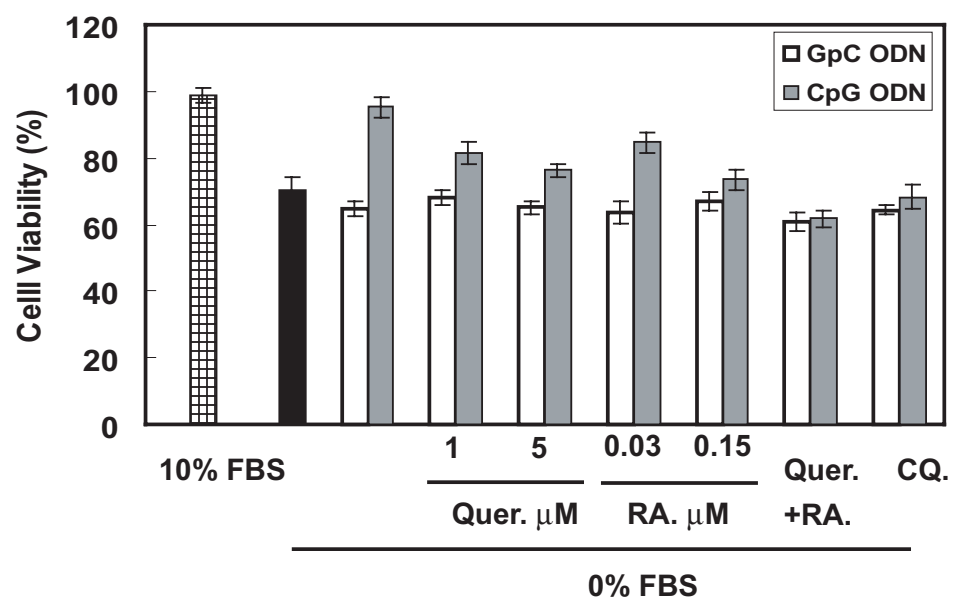

B

\begin{tabular}{|c|c|c|}
\hline $10 \%$ FBS & \multicolumn{2}{|c|}{$0 \%$ FBS } \\
\hline RA. Quer. & GpC & CpG-B ODN \\
\hline & ODN & RA. Quer. \\
\hline
\end{tabular}

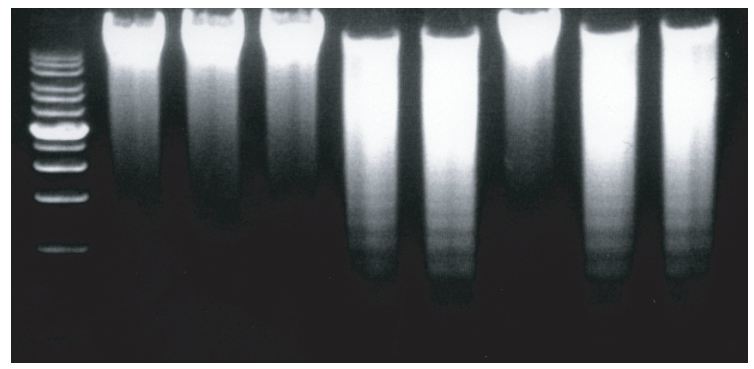

Figure 5. The effects of chloroquine and Hsp inhibitors on the anti-apoptotic effect of CpG-B ODN. (A) Swine PBMC were cultured for $60 \mathrm{~h}$ in serum (10\% FBS) or serum-free (0\% FBS) medium with or without GpC ODN or CpG-B ODN $(1 \mu \mathrm{M})$ in the presence or absence of quercetin (Quer.), radicicol (RA.), Quer. $(5 \mu \mathrm{M})+$ RA. $(0.15 \mu \mathrm{M})$ or chloroquine (CQ., $1 \mu \mathrm{g} / \mathrm{mL})$ as indicated. A trypan blue exclusion assay was used to determine cell viability. Data represent means \pm SD of at least three independent experiments. (B) Swine PBMC were cultured for $60 \mathrm{~h}$ in serum $(10 \%$ FBS) or serum-free ( $0 \%$ FBS) medium with $1 \mu \mathrm{M}$ of CpG-B ODN or GpG ODN in the presence or absence of radicicol $(0.15 \mu \mathrm{M})$ or quercetin $(5 \mu \mathrm{M})$ as indicated. The extent of apoptotic DNA fragmentation was analysed with the use of $2 \%$ DNA agarose gel. The experiment was repeated three times with similar results. 
Table III. Effect of chemical drugs on cell viability of swine PBMC.

\begin{tabular}{lccc}
\hline Treatment $^{\mathrm{a}}$ & \multicolumn{3}{c}{ Viability } \\
\cline { 2 - 4 } & $24 \mathrm{~h}$ & $48 \mathrm{~h}$ & $72 \mathrm{~h}$ \\
\hline Medium & $98.1 \pm 1.5$ & $95.1 \pm 3.2$ & $95.7 \pm 2.6$ \\
Quercetin, $1 \mu \mathrm{M}$ & $96.4 \pm 2.2$ & $97.3 \pm 1.9$ & $96.8 \pm 4.2$ \\
Quercetin, $5 \mu \mathrm{M}$ & $95.7 \pm 3.1$ & $96.4 \pm 2.8$ & $94.9 \pm 2.2$ \\
Quercetin, $10 \mu \mathrm{M}$ & $97.3 \pm 2.5$ & $97.7 \pm 3.4$ & $98.1 \pm 2.8$ \\
Radicicol, $0.1 \mu \mathrm{g} / \mathrm{mL}$ & $98.5 \pm 3.2$ & $98.1 \pm 4.2$ & $96.5 \pm 2.4$ \\
Radicicol, $0.3 \mu \mathrm{g} / \mathrm{mL}$ & $97.5 \pm 1.7$ & $96.9 \pm 3.3$ & $95.3 \pm 2.6$ \\
Chloroquine, $1 \mu \mathrm{g} / \mathrm{mL}$ & $97.3 \pm 2.2$ & $97.8 \pm 1.9$ & $96.1 \pm 2.3$ \\
\hline
\end{tabular}

${ }^{a}$ Swine PBMC $\left(10^{6}\right.$ cells $\left./ \mathrm{mL}\right)$ were cultured with or without drugs at different concentrations for 24,48 , and $72 \mathrm{~h}$. Cell viability was determined using the trypan blue dye exclusion method.

It is noteworthy that CpG-B ODNmediated up-regulation of Hsp90 in swine PBMC was detected by Western blotting but not by $2 \mathrm{D}$ gel electrophoresis analysis (Figs. 2 and 3A). Similarly, up-regulation of Hsp70 by CpG ODN in mouse immune cells was found by Western blot analysis [22]. A likely explanation for the inability to identify the up-regulation of these Hsp by 2-D gel electrophoresis might be due to the limitation in the sensitivity of the technique. Even though 2D gel electrophoresis is a powerful tool to compare the protein expression profiles of cells modulated by specific stimuli, it will be better to follow up the analysis with complementary use of Western blotting.

Members of the HSP family are known to be involved in the regulation of apoptosis [9]. The results from several laboratories have revealed that Hsp70 and Hsp90 protect cells not only from heat, but also from most apoptotic stimuli $[4,9]$. In this study, we found that both Hsp70 and Hsp90 were up-regulated by CpG-B ODN treatment (Fig. 3A) and their inhibitiors suppressed the anti-apoptotic effect of CpG-B ODN (Fig. 5). Our results were consistent with a previous proposal [22] that CpG-B ODN can cause anti-apoptosis via up-regulation of Hsp. Under what kind of conditions does Hsp70 or Hsp90 play more important roles in the CpG-B ODN- mediated anti-apoptosis, however, remains to be evaluated.

Our finding that the supernatant of $\mathrm{CpG}$ B ODN stimulated PBMC did not increase or decrease the expression level of Hsp (Fig. 4B), indicates that this effect of CpG$\mathrm{B}$ ODN is not caused indirectly through other CpG-B ODN-mediated soluble factors. Since CpG-B ODN is known to induce a variety of cytokines such as IL-12, IL-6 and TNF etc. (Fig. 1) [19, 23], a likely explanation is that none of these CpG-B ODN-induced cytokines could affect Hsp70 and Hsp90 expression. An alternative explanation is that due to the cancellation of each other's effect, the net influence of these cytokines on Hsp70 and Hsp90 expression turns out to be negligible. More studies will be needed to clarify whether Hsp and other proteins such as KIAA0857 protein, PNAS-146, V kappa light chain and spondin 1 could be indirectly regulated by each of the CpG-B ODN-induced cytokines.

In summary, by using a $2 \mathrm{D}$ electrophoresis analysis and Western blot, we identified 9 proteins that are effectively up-regulated $24 \mathrm{~h}$ after treatment of swine PBMC with CpG-B ODN. Among these 9 proteins, Hsp60, Hsp70 and Hsp90 are related to anti-apoptosis and cell survival; $\mathrm{V}$ kappa light chain and $\mathrm{T}$ cell receptor variable alpha chain are related to 
immune functions, while spondin 1 and $\mathrm{N}$-acetolactate alpha linked acidic dipeptidase are more likely related to neuron differentiation and growth. The biological activities of another two up-regulated proteins, i.e., KIAA0857 protein, and PNAS146 are yet to be defined. It will be interesting to explore whether these two proteins are involved in the above mentioned effects of CpG-B ODN or other biological functions not yet identified.

\section{ACKNOWLEDGEMENTS}

We thank the core facility for proteomics and technology development at Academia Sinica, Taiwan for mass spectrometry analysis. This study was supported by grant NSC 93-2317-B-001-003 from the National Science and Technology program for Agricultural Biotechnology.

\section{REFERENCES}

[1] Akira S., Hemmi H., Recognition of pathogen-associated molecular patterns by TLR family, Immunol. Lett. (2003) 85:85-95.

[2] Barton G.M., Medzhitov R., Toll-like receptor signaling pathways, Science (2003) 300:1524-1525.

[3] Bauer S., Kirschning C.J., Hacker H., Redecke V., Hausmann S., Akira S., Wagner H., Lipford G.B., Human TLR9 confers responsiveness to bacterial DNA via speciesspecific CpG motif recognition, Proc. Natl. Acad. Sci. USA (2001) 98:9237-9242.

[4] Beere H.M., Stressed to death: regulation of apoptotic signaling pathways by the heat shock proteins, Sci. STKE (2001) 2001:RE1.

[5] Beutler B., Rietschel E.T., Innate immune sensing and its roots: the story of endotoxin, Nat. Rev. Immunol. (2003) 3:169-176.

[6] Beutler B., Hoebe K., Shamel L., Forward genetic dissection of afferent immunity: the role of TIR adapter proteins in innate and adaptive immune responses, C. R. Biol. (2004) 327:571-580.

[7] Bird A.P., CpG-rich islands and the function of DNA methylation, Nature (1986) 321:209-213.

[8] Feinstein Y., Borrell V., Garcia C., BurstynCohen T., Tzarfaty V., Frumkin A., Nose A., Okamoto H., Higashijima S., Soriano E., Klar A., F-spondin and mindin: two structurally and functionally related genes expressed in the hippocampus that promote outgrowth of embryonic hippocampal neurons, Development (1999) 126:3637-3648.

[9] Garrido C., Gurbuxani S., Ravagnan L., Kroemer G., Heat shock proteins: endogenous modulators of apoptotic cell death, Biochem. Biophys. Res. Commun. (2001) 286:433-442.

[10] Guzylack-Piriou L., Balmelli C., McCullough K.C., Summerfield A., Type-A $\mathrm{CpG}$ oligonucleotides activate exclusively porcine natural interferon-producing cells to secrete interferon-alpha, tumour necrosis factor-alpha and interleukin-12, Immunology (2004) 112:28-37.

[11] Hacker H., Mischak H., Miethke T., Liptay S., Schmid R., Sparwasser T., Heeg K., Lipford G.B., Wagner H., CpG-DNAspecific activation of antigen-presenting cells requires stress kinase activity and is preceded by non-specific endocytosis and endosomal maturation, EMBO J. (1998) 17:6230-6240.

[12] Hacker H., Vabulas R.M., Takeuchi O., Hoshino K., Akira S., Wagner H., Immune cell activation by bacterial CpG-DNA through myeloid differentiation marker 88 and tumor necrosis factor receptorassociated factor (TRAF)6, J. Exp. Med. (2000) 192:595-600.

[13] Halpern M.D., Kurlander R.J., Pisetsky D.S., Bacterial DNA induces murine interferon-gamma production by stimulation of interleukin-12 and tumor necrosis factoralpha, Cell. Immunol. (1996) 167:72-78.

[14] Hartmann G., Battiany J., Poeck H., Wagner M., Kerkmann M., Lubenow N., Rothenfusser S., Endres S., Rational design of new $\mathrm{CpG}$ oligonucleotides that combine $B$ cell activation with high IFN-alpha induction in plasmacytoid dendritic cells, Eur. J. Immunol. (2003) 33:1633-1641.

[15] Kamstrup S., Verthelyi D., Klinman D.M., Response of porcine peripheral blood mononuclear cells to CpG-containing oligodeoxynucleotides, Vet. Microbiol. (2001) 78:353-362.

[16] Klinman D.M., Conover J., Coban C., Repeated administration of synthetic oligodeoxynucleotides expressing $\mathrm{CpG}$ motifs provides long-term protection against bacterial infection, Infect. Immun. (1999) 67:5658-5663.

[17] Kobayashi T., Walsh M.C., Choi Y., The role of TRAF6 in signal transduction and the immune response, Microbes Infect. (2004) 6:1333-1338.

[18] Krieg A.M., An innate immune defense mechanism based on the recognition of $\mathrm{CpG}$ motifs in microbial DNA, J. Lab. Clin. Med. (1996) 128:128-133. 
[19] Krieg A.M., CpG motifs in bacterial DNA and their immune effects, Annu. Rev. Immunol. (2002) 20:709-760.

[20] Kumaraguru U., Pack C.D., Rouse B.T., Toll-like receptor ligand links innate and adaptive immune responses by the production of heat-shock proteins, J. Leukoc. Biol. (2003) 73:574-583.

[21] Kuo C.C., Kuo C.W., Liang C.M., Liang S.M., A transcriptomic and proteomic analysis of the effect of CpG-ODN on human THP-1 monocytic leukemia cells, Proteomics (2005) 5:894-906.

[22] Kuo C.C., Liang S.M., Liang C.M., CpG$\mathrm{B}$ oligodeoxynucleotide promotes cell survival via up-regulation of Hsp70 to increase $\mathrm{Bcl}-\mathrm{xL}$ and to decrease apoptosis-inducing factor translocation, J. Biol. Chem. (2006) 281:38200-38207.

[23] Kuo C.C., Lin W.T., Liang C.M., Liang S.M., Class I and III phosphatidylinositol 3'-kinase play distinct roles in TLR signaling pathway, J. Immunol. (2006) 176:5943-5949.

[24] Lenert P., Rasmussen W., Ashman R.F., Ballas Z.K., Structural characterization of the inhibitory DNA motif for the type A (D)CpG-induced cytokine secretion and NKcell lytic activity in mouse spleen cells, DNA Cell Biol. (2003) 22:621-631.

[25] Lund J., Sato A., Akira S., Medzhitov R., Iwasaki A., Toll-like receptor 9-mediated recognition of Herpes simplex virus- 2 by plasmacytoid dendritic cells, J. Exp. Med. (2003) 198:513-520.

[26] Mayo M.W., Madrid L.V., Westerheide S.D., Jones D.R., Yuan X.J., Baldwin A.S. Jr., Whang Y.E., PTEN blocks tumor necrosis factor-induced NF-kappa B-dependent transcription by inhibiting the transactivation potential of the p65 subunit, J. Biol. Chem. (2002) 277:11116-11125.

[27] Medzhitov R., Toll-like receptors and innate immunity, Nat. Rev. Immunol. (2001) $1: 135-145$.

[28] Neckers L., Neckers K., Heat-shock protein 90 inhibitors as novel cancer chemotherapeutic agents, Expert. Opin. Emerg. Drugs (2002) 7:277-288.

[29] Onishi A., Iwamoto M., Akita T., Mikawa S., Takeda K., Awata T., Hanada H., Perry A.C., Pig cloning by microinjection of fetal fibroblast nuclei, Science (2000) 289:1188-1190.

[30] Pangalos M.N., Neefs J.M., Somers M., Verhasselt P., Bekkers M., van der Helm L., Fraiponts E., Ashton D., Gordon R.D., Isolation and expression of novel human glutamate carboxypeptidases with $\mathrm{N}$-acetylated alpha-linked acidic dipeptidase and dipeptidyl peptidase IV activity, J. Biol. Chem. (1999) 274:8470-8483.
[31] Park Y., Lee S.W., Sung Y.C., Cutting Edge: CpG DNA inhibits dendritic cell apoptosis by up-regulating cellular inhibitor of apoptosis proteins through the phosphatidylinositide-3'-OH kinase pathway, J. Immunol. (2002) 168:5-8.

[32] Savill J., Hogg N., Haslett C., Macrophage vitronectin receptor, CD36, and thrombospondin cooperate in recognition of neutrophils undergoing programmed cell death, Chest (1991) 99:6S-7S.

[33] Sechi S., Chait B.T., Modification of cysteine residues by alkylation. A tool in peptide mapping and protein identification, Anal. Chem. (1998) 70:5150-5158.

[34] Shimosato T., Kitazawa H., Katoh S., Tomioka Y., Karima R., Ueha S., Kawai Y., Hishinuma T., Matsushima K., Saito T., Swine Toll-like receptor 9(1) recognizes $\mathrm{CpG}$ motifs of human cell stimulant, Biochim. Biophys. Acta (2003) 1627:56-61.

[35] Sohn W.J., Lee K.W., Choi S.Y., Chung E., Lee Y., Kim T.Y., Lee S.K., Choe Y.K., Lee J.H., Kim D.S., Kwon H.J., CpGoligodeoxynucleotide protects immune cells from gamma-irradiation-induced cell death, Mol. Immunol. (2006) 43:1163-1171.

[36] Tabeta K., Georgel P., Janssen E., Du X., Hoebe K., Crozat K., Mudd S., Shamel L., Sovath S., Goode J., Alexopoulou L., Flavell R.A., Beutler B., Toll-like receptors 9 and 3 as essential components of innate immune defense against mouse cytomegalovirus infection, Proc. Natl. Acad. Sci. USA (2004) 101:3516-3521.

[37] Takeshita F., Gursel I., Ishii K.J., Suzuki K., Gursel M., Klinman D.M., Signal transduction pathways mediated by the interaction of CpG DNA with Toll-like receptor 9, Semin. Immunol. (2004) 16:17-22.

[38] Verthelyi D., Zeuner R.A., Differential signaling by CpG DNA in DCs and B cells: not just TLR9, Trends Immunol. (2003) 24:519522.

[39] Yi A.K., Hornbeck P., Lafrenz D.E., Krieg A.M., CpG DNA rescue of murine B lymphoma cells from anti-IgM-induced growth arrest and programmed cell death is associated with increased expression of c-myc and bcl-xL, J. Immunol. (1996) 157:4918-4925.

[40] Yi A.K., Chang M., Peckham D.W., Krieg A.M., Ashman R.F., CpG oligodeoxyribonucleotides rescue mature spleen B cells from spontaneous apoptosis and promote cell cycle entry, J. Immunol. (1998) 160:58985906. 